\title{
Sciendo
}

Administration, vol. 66, no. 3 (2018), pp. 99-115

doi: 10.2478/admin-2018-0029

\section{Playing catch-up? Adult social care in Northern Ireland}

\author{
Alexandra Chapman \\ Ulster University, Northern Ireland
}

\section{Introduction}

Adult social care in Britain is undergoing a period of major change. This is largely based on the move towards 'self-directed support' for older people using social care services, which has changed how social care policies are developed and implemented. This refers to a range of approaches aimed at enabling people who use social care services to have a greater say in their social care plans to achieve more personalised support. It is inextricably linked with values of choice, control and user participation as opposed to service-led planning (Beresford, 2014; Glasby \& Needham, 2014; Needham, 2011). However, there has been a greater political commitment to achieve this for older people in England, Scotland and Wales compared to Northern Ireland, where similar debates are largely absent.

In the context of devolution, health and social care remain wholly devolved matters. With the distinctiveness of UK systems and policy structures, the landscape of devolution has created the potential for policy divergence in adult social care (Gray \& Birrell, 2012). This paper explores policy developments based on principles of selfdirected support in adult social care across the UK to consider if there are lessons to be learnt from other jurisdictions. Using the model of policy transfer, the paper aims to understand and consider how political ideas and policies could be transferred from one system to 
another. To do so, it outlines the current structure of health and social care in Northern Ireland. It then goes on to analyse relevant policy documents in each jurisdiction. After examining these, it then discusses the pursuit of policies which support self-directed approaches, to consider if this or a similar policy framework could be applied and introduced in Northern Ireland.

\section{Policy transfer in the context of devolution}

The concept of policy transfer has become an increasingly important feature of the contemporary policymaking process and development (Benson \& Jordan, 2011; Dorey, 2014; James \& Lodge, 2003; Dolowitz \& Marsh, 2000). Lodge (2003, p. 161) describes how this refers to 'an application of knowledge of a set of policy instruments of one policy domain into another policy domain'. The transfer of policy is often rational as it is about making choices in policy developments but, as Hulme (2005, p. 419) points out, it is also 'about realising ideological goals'. This process involves deliberate awareness and decision-making to copy and transfer. Drawing on related concepts of lesson-drawing (Rose, 1991), policy learning (Hall, 1993) and policy convergence (Bennett, 1991), Dolowitz \& Marsh developed their own analytical framework, which is now most commonly used within political and social literature and studies in the UK (Benson \& Jordan, 2011). While terminology and definitions vary, the most widely used is described as:

the process, by which knowledge about policies, administrative arrangements, institutions and ideas in one political system (past or present) is used in the development of policies, administrative arrangements, institutions and ideas in another political system. (Dolowitz \& Marsh, 2000, p. 5)

Dolowitz \& Marsh also argue that most forms of transfer will fall between these two extremes of 'lesson-drawing' and 'completely coerced', and that some will also arise from a mixture of both pressures in response to a need for change and dissatisfaction with the status quo. A list of things that could in theory be transferred was also identified by Dolowitz \& Marsh (1996, p. 349). This included 'policy goals, structure and context, policy instruments or administrative techniques; institutions; ideology; ideals, attitudes and concepts'. With this in mind, Evans \& Davies (1999) categorised policy transfer as 
'soft' and 'hard'. Initially, studies primarily focused on the 'hard' transfer of policy practice, instruments and implementation (Jones \& Newburn, 2006) but recent attention has been paid to 'soft' transfer, including the transfer of ideas, ideologies and concepts which influence policy agendas. Benson \& Jordan (2011) highlight how policy transfer goes beyond the traditional elements of policy as it is now further extending the boundaries of what the concept means. McCann \& Ward (2012) align themselves with a more socially constructed view of transfer, which emphasises how policies transform as they move through time and space. They suggest policy constructed in this way avoids any assumptions that policies emerge in full form from a specific place or that they circulate unchanged.

Literature on policy transfer has many similarities with the lessondrawing literature (Stone, 2004). While policy transfer is concerned with understanding the general process of transferring policies, lessondrawing considers the 'conditions under which policies or practices operate' that are used to engage in policy transfer (Page, 2000, p. 2). Rose (1991, p. 7) describes this process as a 'deliberate choice' to learn about policy from another country and implies that policymakers can learn the new policy voluntarily. Rose (1993, p. 46) also asserts that if politicians adopt lessons solely on the ground of the desirability of goals without regard to the feasibility of mean, they run the risk of backing a shipwrecked program'. As the previous section demonstrated, similar values of greater personalised care can be found across the UK. Simpson (2017, p. 217) suggests the desire to copy a given policy or 'simply to "keep up" with one's neighbours' may also increase the need for additional legislation - albeit any policy must adapt to fit the individual context. This is important as health and social care structural arrangements, values and principles differ in each jurisdiction, and it cannot be assumed that the same policy concept (i.e. personalisation agenda) could work in a different context (i.e. Northern Ireland).

\section{Structure of health and social care in Northern Ireland}

Northern Ireland is constitutionally part of the UK and much of its policy, law and professional practice in adult social care is similar to that experienced in Britain (Campbell \& McLaughlin, 2000). However, policy directions and implementation for adult social care are becoming diverse. As a devolved matter, the Northern Ireland Assembly have adopted their own strategies for adult social care. In a 
broader policy and practice context at both national and local level, this section will consider if and how policymakers in the devolved jurisdictions have taken a different approach and interpretation to practising and implementing the objectives of a person-centred model for adult social care policy.

Since 1973 Northern Ireland has operated under an integrated structure of health and social care. This system has attracted much attention and Heenan \& Birrell (2006, p. 48) assert it is 'one of the most structurally integrated and comprehensive models of health and personal social services in Europe'. It was anticipated that this would provide a comprehensive structure in which to decide priorities, develop policies and work together towards a common goal of meeting the total needs of individuals, families and communities for health and social care services. While this joined-up system has demonstrated a working model of integration, it has also been subject to criticism, often associated with difficulties in managing both health and social care together (Hudson \& Henwood, 2002). In terms of community care provision, Field \& Peck (2003) identify similarities between Britain and Northern Ireland, including delayed discharges from hospital. In other parts of the UK, the lack of integration between the National Health Service (NHS) and local authority social services has been identified as problematic and there is now greater desire for a joined-up approach (Goodwin et al., 2013). More recently, Scotland has created a number of new public organisations, known as 'integration authorities', placing integration of health and social care services on statutory footing, introduced under the Public Bodies (Joint Working) (Scotland) Act, 2014. However, Heenan \& Birrell (2009) question whether the full potential of an integrated structure in Northern Ireland has been realised.

The Department of Health ${ }^{1}(\mathrm{DoH})$ is responsible for adult social care in Northern Ireland including the authorising and allocation of government funding. Services are commissioned by a single large body, the Health and Social Care Board, advised by local commissioning groups and delivered by five trusts (Belfast, South Eastern, Southern, Northern and Western) (Birrell \& Heenan, 2014). A sixth trust covers the ambulance services which operate at regional level. This system has been in place since the Health and Social Care (Reform) Act (Northern Ireland), 2009. It was anticipated that the

${ }^{1}$ Previously named the Department of Health, Social Services and Public Safety until 2017. 
reform would enable a greater patient-led and patient-centred integrated system. Figure 1 (below) demonstrates the current structure of health and social care in Northern Ireland.

Figure 1: Health and social care structure in Northern Ireland

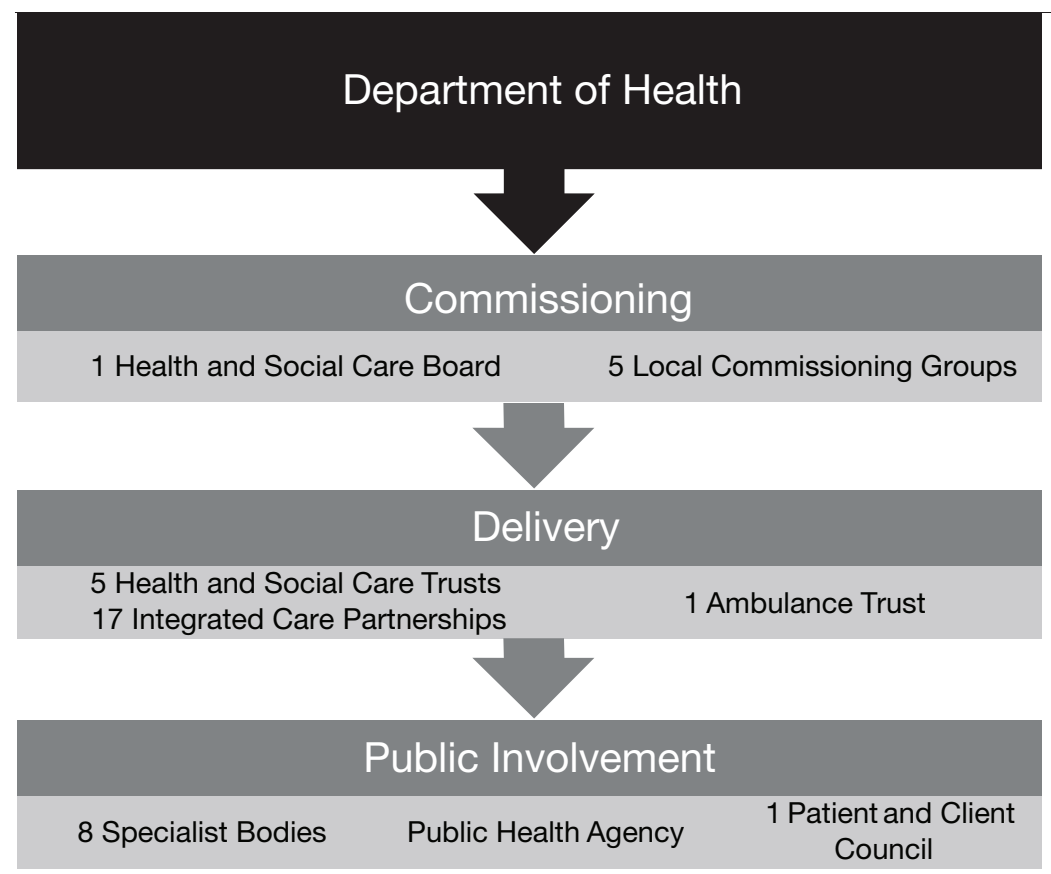

The Patient and Client Council provides an independent voice for patients, carers and communities, covering adult, children and health services. The Public Health Agency is responsible for improving the health and well-being of the population. However, this delivery model is dominated by quangos and has been criticised as meaning weak user and public involvement and little local accountability or responsiveness (Heenan \& Birrell, 2009). As part of Transforming Your Care (Department of Health, Social Services and Public Safety (DHSSPS), 2011), seventeen integrated care partnerships (ICPs) were established within the five trusts (DHSSPS, 2012). Part of the rationale for ICPs was to bring a more integrated approach to service planning and delivery (DHSSPS, 2014). It was also anticipated that ICPs would help bring together health and social care providers from both statutory 
and voluntary sectors to improve patients' journeys between and within hospital and community care, and reduce hospital admission. However, they have been criticised in terms of the unclear relationship with current health and social care structures, progress, performance and outcome (Birrell \& Heenan, 2014; Gray \& Birrell, 2016).

\section{Commissioning in health and social care}

Following the Donaldson report (DHSSPS, 2015) and the department's own review of commissioning, it was identified that the current system is flawed and is not working as effectively as predicted in 2009. The current model of health and social care has been described as a system that 'has multiple layers, intricate layers of decision-making and unclear lines of accountability' (DHSSPS, 2016, p. 2). The report recommended that the commissioning system should be redesigned to make it simpler and more capable of reshaping services for the future. It also concluded that the current system suffers from a lack of transparency. In addition, it acknowledged that there was widespread uncertainty about who is in charge of the system, amplifying the lack of visible clarity around the system in Northern Ireland. This was also noted in Power to People: Proposals to Reboot Adult Social Care and Support in Northern Ireland (DoH, NI, 2017), which found that public understanding of the care system is limited and that some often incorrectly assume it is part of the NHS.

The system used to commission domiciliary care services for formal care at home has been described as difficult to understand, and there appears to be high levels of 'inconsistency in the planning and delivery of services across Northern Ireland' (Duffy et al., 2015, p. 18). Commissioning has also been criticised in terms of the lack of integrated approaches and requirements, with the focus mostly being on the procurement of a service (Gray \& Birrell, 2016). Care packages are delivered either by statutory providers (operated by health and social care (HSC) trusts) or by contracting an independent provider (voluntary or private sector). Recent figures published by the DoH, NI (2017) show that the independent sector provides most domiciliary care in Northern Ireland. However, there is limited evidence regarding the implications of this for integrated care between domiciliary care and other services.

Given the means-tested nature of social care, HSC trusts can choose when to charge for care and support provided in a person's 
home based on a person's ability to pay, considering their savings and investments. People aged over seventy-five are not charged. HSC trusts are also responsible for assessing an individual's finances if they require care home provision through a financial assessment looking at income (state pension, pension credit and interest on savings) and capital (savings, investment and property). The current threshold in Northern Ireland is set at $£ 23,250$ in capital. However, research from the Northern Ireland Life and Times (NILT) survey ${ }^{2}$ found respondents were unaware that social care is funded and accessed differently from the NHS, and that individuals can be liable to contribute to the cost of care (Gray \& Devine, 2017). This is likely to be the case, as these two services are often treated very differently in terms of policy priority and public funding, where issues relating to acute health care continue to dominate. It also found that many were strongly opposed to the idea that everyone should have to pay for their social care. There have been relatively fewer policy discussions on reforming how social care is funded despite growing recognition for a complete reform of the entire system.

\section{Personalising adult social care in Great Britain: The policy context}

Promoting a greater personalised model of care and minimising institutional care is a long-established policy aim throughout the UK. The need to develop a new care and support system to ensure individuals have a say in how services are designed, developed and delivered was outlined in Our Health, Our Care, Our Say (Department of Health, 2006). In England self-directed support has been rolled out under a personalisation agenda. It was first placed on a statutory footing by the Labour Government in Putting People First: A Shared Vision and Commitment to the Transformation of Adult Social Care (HM Government, 2007). The policy outlined that greater personcentred planning would become mainstream to ensure packages of support could be tailored to individual needs. The genesis lies in much older campaigns to increase choice and independence for people using care services (Glasby \& Littlechild, 2009). The introduction of

2 Annual survey has put on record the attitudes, values and beliefs of the people in Northern Ireland to a wide range of social policy issues. The survey has previously contained questions on adult social care (2010 and 2015). 
personalisation has influenced the direction of delivery and implementation in care services in England. Scotland and Wales have followed a similar approach by expressing a greater desire to develop adult social care policies underpinned by values of independence, participation and choice. However, England, Scotland and Wales have pursued and implemented their own distinct model for achieving greater personalised care.

Debates about personalisation as adopted in England often focus on the contested nature of the ideologies underpinning its development and subsequent introduction (Glasby \& Needham, 2014; Slasberg et al., 2012). Scotland and Wales used their devolved powers to introduce a different model of care to personalisation for several reasons, including disagreement over the ideologies underpinning its approach in social care practice. In Scotland a greater emphasis is placed on user and carer involvement underpinned by the ethos of coproduction for adult social care (Gray \& Birrell, 2016; Mooney \& Scott, 2012). Following proposals outlined in the national strategy, Self-Directed Support (Scottish Government, 2010), new legislation for social care was introduced under the Social Care (Self-directed Support) (Scotland) Act, 2013. This allowed social care users to decide how much control and responsibility they have over their own support arrangements. In Wales the policy document Sustainable Social Services for Wales (Welsh Assembly Government, 2011) included discussions on providing greater control for users and a more personalised approach in adult social care, often referred to as 'citizen-directed support' (Duffy, 2012; Gray \& Birrell, 2013). The Welsh Government's Social Services and Well-being Act, 2014, was implemented in 2016 to transform the way social care is delivered, supporting greater user involvement, control and integration. Akin to Scotland, Wales rejected the English model of personalisation, as it was perceived to be a strategy of retrenchment, in favour of renewal, delivery and innovation (Welsh Assembly Government, 2011).

The same principles and values underpinning adult social care policy in England, Scotland and Wales can be found to achieve the same outcome - greater personalised care and support for social care users. Deacon (2000, p. 13) points out that policymakers may arrive independently at the same conclusions, without any conscious process of transfer, as 'convergence of ideas does not necessarily imply that one thinker has influenced the other'. Therefore, policy transfer is not necessarily a prerequisite for policy convergence. 


\section{Policy developments in Northern Ireland}

Policy developments in Northern Ireland are more limited than in other parts of the UK and there are few strategies dedicated specifically to adult social care (Gray \& Birrell, 2013). In addition, Heenan \& Birrell (2010, p. 136) observe that, other than integrated structuring, there have been 'no major legislative innovations in Northern Ireland'. The current legislation for adult social care is provided through several laws dating back to 1978 (Duffy et al., 2015), and community care provision continues to operate under the principles set out in the 1990 People First: Community Care in Northern Ireland (Department of Health and Social Services, NI, 1990). However, given the greater demand of care services, rising expectations about care and shifting focus towards greater personalised care, it is widely recognised as out of date, unfit for purpose and unable to provide the best standard of care services for older people. The need for a new legislative framework in adult social care has been identified. To modernise the current system, several reviews in health and social care have taken place since 2010 (DHSSPS, 2011, 2015, 2016). However, these have mostly focused on health reform, and less attention has been paid to reform of adult social care, limiting the ability to develop user-led services and greater participation for those who use care and support services.

Transforming Your Care: A Review of Health and Social Care in Northern Ireland (DHSSPS, 2011) included a range of broad proposals for the future shape of services. The core objective of the review was to shift the delivery of services away from hospital and into the community by placing individuals at the centre of the model by promoting a better outcome for the service user, carer and their family' (DHSSPS, 2011, p. 5). In practical terms, the review proposed to move $£ 83$ million away from hospital care and give it to primary, community and social care services. The anticipated outcome of bringing care closer to home and providing users with more choice and greater independence has yet to be realised, given the limited progress that the review has made. Some reference to 'personalisation' was made in the review and the subsequent Who Cares? The Future of Adult Social Care and Support in Northern Ireland (DHSSPS, 2012) document. However, neither review outlined what the term 'personalisation' would mean in practice, beyond greater support for a system of care that promotes care closer to home and provides users with greater choice. Themes of user involvement and user control, 
which have been central to adult social care transformations in Britain, are largely ignored (Gray \& Birrell, 2013; Ham et al., 2013).

Following the limited progress made since Transforming Your Care, a further two health and social care reports were commissioned: the Donaldson report (DHSSPS, 2015) and Bengoa report (DHSSPS, 2016). Sir Liam Donaldson was tasked with investigating the quality of government arrangements for the overall system. The report, The Right Time, the Right Place, recognised the importance of Transforming Your Care, finding that both service users and providers felt that it was 'simply not being implemented', nor was it properly planned or funded (DHSSPS, 2015, p. 14). The report also noted that commissioning needed strengthening to make the system simpler and proposed a new timeline implementation plan. In the latest attempt to reform health and social care, a report led by Professor Rafael Bengoa was commissioned. Systems, Not Structures - Changing Health and Social Care (DHSSPS, 2016) and the department's subsequent strategy, Health and Wellbeing 2026: Delivering Together, were both published in 2016. The Bengoa report acknowledged that:

care should be personalised, preventative, participative and predictive. However, none of those objectives can be achieved in the present reactive and fragmented system. The HSC therefore requires a new organisational form at the local delivery level, an organisational arrangement which will allow those approaches to be embedded in the culture of everyday health care. (DHSSPS, 2016, p. 42)

While these strategic documents appear to endorse a similar rhetoric of moving policy towards a personalised system of care, they also highlight how the current model of care is unorganised and continues to operate in silos. Based on this premise, it is difficult to envisage how a person-centred approach could be implemented and achieved in the current system, hence the need for a fundamental reform of adult social care policy and legislation.

Policy developments in Northern Ireland have not occurred at the same pace as the rest of the UK. As a result of criticism of the lack of focus on social care in the various reviews of the health and social care system, some efforts have been made to address this. As mentioned, in 2012 the department published for consultation a brief discussion paper Who Cares? The Future of Adult Social Care and Support in Northern Ireland (DHSSPS, 2012). In 2016 the department announced 
the setting up of an 'expert advisory panel' to support its work in developing proposals for reform to the adult social care system. Its report, Power to People: Proposals to Reboot Adult Care and Support in Northern Ireland (DoH, NI, 2017), echoes the promotion and value of person-centred care and of a shift away from institutionalised services, but did not include or outline an allocated budget to achieve such change. The report also identified sixteen proposals for change, with plans to develop a new concordat. It states that a concordat would provide:

the opportunity to engage the wider public in a conversation about what adult social care and support should be, how it should be organised and managed, who might deliver services and how they should be costed and funded. (DoH, NI, 2017, p. 85)

Other than proposing for a model of self-directed support to become standardised and to introduce one stream of charging for all care services (means-testing both domiciliary care and residential care), the report did not outline how this could be achieved in practice or what this would mean for adult social care users.

\section{Self-directed care in practice}

Self-directed support for older people is delivered and practised differently across the UK. However, it is largely operated though mechanisms such as direct payments and personal budgets, giving individuals the financial resources to meet their own care needs. Policy initiatives for cash-for-care schemes were introduced in the 1990s, following years of campaigning by disability organisations (Leece \& Bornat, 2006). Initially targeted towards people with physical disabilities, this has gradually expanded to all groups of people eligible for care provision. Underpinned by principles for greater autonomy, independence, choice and control, it was envisaged that direct payments could also reduce barriers to inclusion and participation (Glasby \& Littlechild, 2016). It has also been emphasised that it is significantly cheaper to give individuals a direct payment to meet their own care than it is for their care to be arranged by the state. Arguably, this has increased individual responsibility for providing social care.

To an extent, the implementation of direct payments across the UK represents one example of policy convergence in adult social care. 
Under the Carers and Direct Payments Act (Northern Ireland), 2002 (DHSSPS, 2002), eligible social care users are entitled to cash payments in lieu of regular social services, designed to increase choice and independence by enabling service users to have greater control over their own financial resources (Gray \& Birrell, 2013). Although these are operational in each UK jurisdiction, Riddell et al. (2006) found some disparities in the uptake of direct payments, with the highest in England and the lowest in Northern Ireland. Gray \& Birrell (2013) propose this could be linked to the absence of any real policy debates about the use of direct payments in Northern Ireland and also to the small number of independent organisations providing advice and support to users.

In England, personal budgets have also been equated to personalisation. Personal budgets are now a mandatory part of all care plans (since the Care Act, 2014) and involve a needs-based allocation of money after an assessment sufficient to meet the person's needs. While personal budgets have brought many tangible benefits to service users, they have attracted strong responses - both positive and negative. The National Personal Budget Survey (2011) found that the usefulness of personal budgets for working-age adults was not apparent for older people (Hatton \& Waters, 2011). Woolham \& Benton (2012) contend they have only empowered those with the capacity and willingness to engage in the market - predominately young disabled adults, compared to older care users. The uptake of personal budgets across different user groups remains an issue.

A model of self-directed support is currently being rolled out in Northern Ireland. As outlined by the Health and Social Care Board, individuals can choose how their support is provided and one option is to take this as a direct payment or a 'managed' budget. While this model is considered as 'best practice' by social care services, no strategic guidelines or a legislative framework for it exists, and there is very little research or information available in Northern Ireland.

Opponents of personalisation are more likely to suggest that the policy is largely influenced by consumerist principles, while advocates would associate it with values of empowerment, autonomy and choice. Despite these disparities, policy developments in Britain have been informed and influenced by the same aim, which is to achieve a more personalised approach for those using social services. This appears to take centre stage in adult social care debates in England, Scotland and Wales, compared to Northern Ireland, where similar discussions are not taking place to the same extent. 


\section{Discussion and conclusion}

Devolution adds an additional dimension by creating four policy arenas for the formulation and development of adult social care policies with separate legislative and administrative bodies. This landscape has created the potential for more policy divergence in social care (Gray \& Birrell, 2012). It is clear that this is not a straightforward debate as the ideologies driving reform in adult social care and in each UK jurisdiction are often complicated and reflect differing approaches, ideologies and motivations.

Existing literature would imply that there are some reasons why policy transfer may take place. The focus is on England, where there is greater political commitment to achieving personalised care, and this has attracted a higher policy profile compared to the other three UK jurisdictions (Needham, 2011). For this reason, the process related to the 'success' of policy transfer as described by Dolowitz \& Marsh (2000) depends on the information about the policy and how it works in the country of origin. Personalisation has reshaped public services in England, particularly adult social care. There is the opportunity to learn from this policy narrative. Gray \& Birrell (2012) suggest that a system of devolution seems likely to facilitate and lead to policy transfer or copying for many reasons. They also state that the process and opportunity for policy transfer are more likely to occur when a government is reforming an existing system. This is of importance as the need to reform adult social care has been widely identified in Northern Ireland.

There are also several reasons why policy transfer may not take place. Firstly, Northern Ireland has a structurally integrated system of health and social care unlike in the rest of the UK and, as noted previously, more emphasis has been placed on health reform and less attention on adult social care. Dolowitz \& Marsh (2000) emphasise that contextual factors such as different political and commissioning structures may create constraints within the policy process. Secondly, the direction of social care in other parts of the UK, mainly England, has been influenced by a drive towards consumerism and marketisation (Glasby, 2012; Needham, 2011). Such ideological debates have been absent in Northern Ireland. For this reason, thirdly, there is uncertainty about what self-directed support should look like for social care users in Northern Ireland. While there have been three major reviews of health and social care since 2010 (DHSSPS, 2011, 2015, 2016), and more recently two reports on adult social care (DHSSPS, 
2012; DoH, NI, 2017), none have outlined exactly what reforming the system will look like in the future beyond broad support for a more personalised model of care.

While some progress has been made in reforming the system of adult care and support in Northern Ireland, this paper highlights that significant work remains. In terms of policy, there is no clarity about how self-directed support will work in practice beyond providing users with greater choice and control when making care arrangements. A high degree of centralisation and managerialism prevails, making it difficult for local government to operate in the delivery of health and social care compared to other jurisdictions. Policy divergence in adult social care continues as other devolved jurisdictions are progressively working towards new models of care that are underpinned by principles of user involvement, choice and control. These debates are noticeably absent in Northern Ireland; nonetheless, there is the opportunity to learn from other UK jurisdictions to ensure that reform can successfully work for current and future social care users. For this to happen, older people need to be well informed about their entitlement and rights to care services to allow them to make decisions regarding their care. It is clear that reform of adult social care and support is urgently required in Northern Ireland.

\section{References}

Bennett, C. (1991). What is policy convergence and what causes it? British Journal of Political Science, 21 (1), 215-33.

Benson, D., \& Jordan, A. (2011). What have we learned from policy transfer research? Dolowitz and Marsh revisited. Political studies review, 9 (3), 366-78.

Beresford, P. (Ed.) (2014). Personalisation. Bristol: Policy Press.

Birrell, D., \& Heenan, D. (2014). Integrated care partnerships in Northern Ireland: Added value or added bureaucracy? Journal of Integrated care, 22 (6), 197-207.

Campbell, J., \& McLaughlin, J. (2000). The ‘joined up' management of adult health and social care services in Northern Ireland: Lessons for the rest of the UK? Journal of Integrated Care, 8 (5), 6-13.

Deacon, A. (2000). Learning from the US? The influence of American ideas upon 'new labour' thinking on welfare reform. Policy \& Politics, 28 (1), 5-18.

Department of Health. (2006). Our health, our care, our say: A new direction for community services (Vol. 6737). London: The Stationery Office.

Department of Health and Social Services, NI. (1990) People first: Community care in Northern Ireland for the 1990s. Belfast: HMSO. 
DHSSPS. (2002). Carers and Direct Payments Act (Northern Ireland) 2002. Belfast: DHSSPS.

DHSSPS. (2011). Transforming your care: A review of health and social care in Northern Ireland. Belfast: DHSSPS.

DHSSPS. (2012). Who cares? The future of adult social care and support in Northern Ireland (consultation). Belfast: DHSSPS.

DHSSPS. (2014). Health and social care (commissioning plan) direction Northern Ireland. Belfast: DHSSPS.

DHSSPS. (2015). The right time, the right place [Donaldson report]. Belfast: DHSSPS.

DHSSPS. (2016). Systems, not structures - Changing health and social care [Bengoa report]. Belfast: DHSSPS.

DoH, NI. (2017). Power to people: Proposals to reboot adult social care and support in Northern Ireland. Belfast: Department of Health.

Dolowitz, D., \& Marsh, D. (1996). Who learns what from whom: A review of the policy transfer literature. Political studies, 44 (2), 343-57.

Dolowitz, D. P., \& Marsh, D. (2000). Learning from abroad: The role of policy transfer in contemporary policy-making. Governance, 13 (1), 5-23.

Dorey, P. (2014). Policy making in Britain. London: Sage.

Duffy, S. (2012). Is personalisation dead? London: Centre for Welfare Reform.

Duffy, J., Basu, S., Davidson, G., \& Pearson, K. C. (2015). Review of legislation and policy guidance relating to adult social care in Northern Ireland. Belfast: Commissioner for Older People.

Evans, M., \& Davies, J. (1999). Understanding policy transfer: A multi-level, multi-disciplinary perspective. Public administration, 77 (2), 361-85.

Field, J., \& Peck, D. (2003). Mergers and acquisitions in the private sector: What are the lessons for health and social services? Social Policy \& Administration, 37 (7), 742-55.

Glasby, J. (2012). Whose risk is it anyway? Risk and regulation in an era of personalisation. York: Joseph Rowntree Foundation.

Glasby, J., \& Littlechild, R. (2009). Direct payments and personal budgets: Putting personalisation into practice. Bristol: The Policy Press.

Glasby, J., \& Littlechild, R. (2016). Direct payments and personal budgets: Putting personalisation into practice (3rd edn). Bristol: Policy Press.

Glasby, J., \& Needham, C. (2014). Debates in personalisation. Bristol: The Policy Press.

Goodwin, N., Sonola, L., Thiel, V., \& Kodner, D. L. (2013). Co-ordinated care for people with complex chronic conditions. London: The King's Fund.

Gray, A. M., \& Birrell, D. (2012). Coalition government in Northern Ireland: Social policy and the lowest common denominator thesis. Social policy and society, 11 (1), 15-25.

Gray, A. M., \& Birrell, D. (2013). Transforming adult social care: Contemporary policy and practice. Bristol: The Policy Press.

Gray, A. M., \& Birrell, D. (2016). Delivering social welfare: Governance and service provision in the UK. Bristol: The Policy Press. 
Gray, A. M., \& Devine, P. (2017). No change: Northern Ireland attitudes and social care policy. ARK research update. Retrieved from http://www.ark.ac.uk/publications/updates/update114.pdf [17 July 2018].

Hall, P. A. (1993). Policy paradigms, social learning, and the state: The case of economic policymaking in Britain. Comparative Politics, 25 (3), 275-96.

Ham, C., Edwards, N., \& Brooke, B. (2013). Leading health care in London: Time for a radical response. London: The King's Fund.

Hatton, C., \& Waters, J. (2011). The national personal budget survey. Wythall: In Control.

Heenan, D., \& Birrell, W. D. (2006). The integration of health and social care: The lessons from Northern Ireland. Social Policy \& Administration, 40 (1), 47-66.

Heenan, D., \& Birrell, D. (2009). Organizational integration in health and social care: Some reflections on the Northern Ireland experience. Journal of Integrated Care, 17 (5), 3-12.

Heenan, D., \& Birrell, D. (2010). Devolution and social security: The anomaly of Northern Ireland. Journal of Poverty and Social Justice, 18 (3), 28-93.

HM Government. (2007). Putting people first: A shared vision and commitment to the transformation of adult social care. London: Department of Health.

Hudson, B., \& Henwood, M. (2002). The NHS and social care: The final countdown. Policy \& Politics, 30 (2), 153-66.

Hulme, R. (2005). Policy transfer and the internationalisation of social policy. Social policy and society, 4 (4), 417-25.

James, O., \& Lodge, M. (2003). The limitations of 'policy transfer' and 'lesson drawing' for public policy research. Political studies review, 1 (2), 179-93.

Jones, T., \& Newburn, T. (2006). Policy transfer and criminal justice. Milton Keynes: Open University Press.

Leece, J., \& Bornat, J. (2006). Developments in direct payments. Bristol: The Policy Press.

Lodge, M. (2003). Institutional choice and policy transfer: Reforming British and German railway regulation. Governance, 16 (2), 159-78.

McCann, E., \& Ward, K. (2012). Policy assemblages, mobilities and mutations: Toward a multidisciplinary conversation. Political Studies Review, 10 (3), 325-32.

Mooney, G., \& Scott, G. (2012). Social justice and social policy in Scotland. Bristol: Policy Press.

Needham, C. (2011). Personalising public services: Understanding the personalisation narrative. Bristol: Policy Press.

Page, E. C. (2000). Future governance and the literature on policy transfer and lesson drawing. Retrieved from http://personal.lse.ac.uk/Pagee/Papers/ EdPagePaper1.pdf [16 July 2018].

Riddell, S., Priestley, M., \& Pearson, C. (2006). Disabled people and direct payments: A UK comparative study. Retrieved from http://www.docs.hss.ed. ac.uk/education/creid/Projects/10i_Directpyts_FinalRpt_I.pdf [16 July 2018]. 
Rose, R. (1991). What is lesson drawing? Journal of Public Policy, 11 (3) 3-30.

Rose, R. (1993). Lesson-drawing in public policy: A guide to learning across time and space (Vol. 91). Chatham, NJ: Chatham House Publishers.

Scottish Government. (2010). Self-directed support: A national strategy for Scotland. Edinburgh: Scottish Government.

Simpson, M. (2017). The social union after the coalition: Devolution, divergence and convergence. Journal of Social Policy, 46 (2), 251-68.

Slasberg, C., Beresford, P., \& Schofield, P. (2012). How self directed support is failing to deliver personal budgets and personalisation. Research, Policy and Planning, 29 (3), 161-77.

Stone, D. (2004). Transfer agents and global networks in the 'transnationalization' of policy. Journal of European Public Policy, 11 (3), $545-66$.

Welsh Assembly Government. (2011). Sustainable social services for Wales: A framework for action. Cardiff: Welsh Assembly Government.

Woolham, J., \& Benton, C. (2012). The costs and benefits of personal budgets for older people: Evidence from a single local authority. British Journal of Social Work, 48 (8), 1472-91. 